\title{
Hedelmällisyyden ja eläimen koon perinnölliset tunnusluvut siniketulla
}

Jussi Peura ${ }^{1)}$, Ismo Strandén ${ }^{1)}$ ja Kerstin Smeds ${ }^{2)}$

1)MTT kotieläintuotannon tutkimus, 31600 Jokioinen, etunimi.sukunimi@mtt.fi

2)Suomen Turkiseläinten Kasvattajain Liitto, 01601 Vantaa, kerstin.smeds@stkl-fpf.fi

\section{Johdanto}

Sinikettujen jalostuksessa pääpaino on viime aikoina ollut koon kasvattamisessa. Koska eläimen koko on hyvin periytyvä ominaisuus, koon fenotyyppinen valinta on tehokas tapa kasvattaa kettupopulaation keskimääräistä kokoa. Eläimen koon ja nahan pituuden välillä on korkea (0.93) geneettinen korrelaatio (Peura ja Strandén 2003). Keskimääräinen nahan koko onkin kasvanut viimeisen 10-15 vuoden aikana nopeasti. Koon kasvun yhä kiihtyessä 2000-luvun vaihteessa, sinikettujen pentutulos eli pentujen keskimääräinen lukumäärä paritettua naarasta kohden on kääntynyt lievään laskuun. Siniketuilla koon ja hedelmällisyyden välistä yhteyttä on selvitetty vähän mutta minkeillä tehdyissä tutkimuksissa on todettu epäsuotuisa geneettinen yhteys koon ja hedelmällisyyden välillä (Lagerqvist ym. 1994). Tämän tutkimuksen tarkoituksena olikin selvittää siniketun, eli tarhatun naalin (Alopex lagopus), tumman värimuodon hedelmällisyyden ja koon välisiä geneettisiä yhteyksiä. Tavoitteena oli selvittää, onko pentuekoon ja eläimen koon välillä epäsuotuisa geneettinen yhteys. Tavoitteena oli myös selvittää miten eläimen koon perinnöllinen kasvu vaikuttaa naaraiden sukukypsyysiän saavuttamiseen.

\section{Aineisto ja menetelmät}

Tutkimuksessa käytetty aineisto saatiin Suomen Turkiseläinten Kasvattajain Liiton ylläpitämästä Sampo-jalostusohjelmasta. Varianssikomponenttien arviointia varten aineistosta poimittiin 18 turkistilaa, joiden tiedettiin vaihtaneen eläinainesta keskenään. Naaraat, jotka oli tarkasteluvuonna paritettu hopeakettu-uroksella tai useammalla kuin yhdellä uroksella poistettiin aineistosta.

Hedelmällisyyttä kuvaavina mittoina käytettiin kolmea ensimmäistä pentuekokoa (PK I-III) ja ikää ensimmäistä kertaa siemennettäessä (IES). IES:ssä hyväksyttiin 271 ja 361 päivän välille sijoittuvat havainnot. Eläimen kokoa (EK) kuvaavana mittana käytettiin tarhaajien silmävaraisesti tekemää kokoarvostelua, jossa asteikko on yhdestä viiteen $(1=$ pienin, $5=$ suurin ja keskiarvo/tila/vuosi $=3)$.

Varianssi- ja kovarianssikomponentit arvioitiin sekä yhden että monen ominaisuuden eläinmalleilla DMU ohjelmalla (Madsen ja Jensen 2000) joka perustuu restricted maximum likelihood (REML) menetelmään. Mallia (1) käytettiin yhden ominaisuuden analyyseissä PK I:1le, IES:1le ja EK:lle:

$\mathbf{y}=\mathbf{X b}+\mathbf{W c}+\mathbf{Z a}+\mathbf{e}$

jossa $\mathbf{y}$ on havaintovektori, $\mathbf{b}$ on kiinteiden tekijöiden vektori, $\mathbf{c}$ ja $\mathbf{a}$ ovat satunnaisten pentue- ja eläintekijöiden vektorit ja $\mathbf{e}$ on jäännöstekijöiden vektori. $\mathbf{X}, \mathbf{W}$ ja $\mathbf{Z}$ ovat kiinteisiin tekijöihin sekä pentue ja eläintekijöihin liittyvät insidenssimatriisit. Mallia (2) käytettiin monenominaisuuden analyyseissä:

$$
\left[\begin{array}{l}
\mathbf{y}_{1} \\
\mathbf{y}_{2} \\
\mathbf{y}_{3} \\
\mathbf{y}_{4} \\
\mathbf{y}_{5}
\end{array}\right]=\left[\begin{array}{lllll}
\mathbf{X}_{1} & \mathbf{0} & \mathbf{0} & \mathbf{0} & \mathbf{0} \\
\mathbf{0} & \mathbf{X}_{2} & \mathbf{0} & \mathbf{0} & \mathbf{0} \\
\mathbf{0} & \mathbf{0} & \mathbf{X}_{3} & \mathbf{0} & \mathbf{0} \\
\mathbf{0} & \mathbf{0} & \mathbf{0} & \mathbf{X}_{4} & \mathbf{0} \\
\mathbf{0} & \mathbf{0} & \mathbf{0} & \mathbf{0} & \mathbf{X}_{5}
\end{array}\right]\left[\begin{array}{l}
\mathbf{b}_{1} \\
\mathbf{b}_{2} \\
\mathbf{b}_{3} \\
\mathbf{b}_{4} \\
\mathbf{b}_{5}
\end{array}\right]+\left[\begin{array}{llllll}
\mathbf{W}_{1} & \mathbf{0} & \mathbf{0} & \mathbf{0} & \mathbf{0} \\
\mathbf{0} & \mathbf{W}_{2} & \mathbf{0} & \mathbf{0} & \mathbf{0} \\
\mathbf{0} & \mathbf{0} & \mathbf{W}_{3} & \mathbf{0} & \mathbf{0} \\
\mathbf{0} & \mathbf{0} & \mathbf{0} & \mathbf{W}_{4} & \mathbf{0} \\
\mathbf{0} & \mathbf{0} & \mathbf{0} & \mathbf{0} & \mathbf{W}_{5}
\end{array}\right]\left[\begin{array}{l}
\mathbf{c}_{1} \\
\mathbf{c}_{2} \\
\mathbf{c}_{3} \\
\mathbf{c}_{4} \\
\mathbf{c}_{5}
\end{array}\right]+\left[\begin{array}{lllll}
\mathbf{Z}_{1} & \mathbf{0} & \mathbf{0} & \mathbf{0} & \mathbf{0} \\
\mathbf{0} & \mathbf{Z}_{2} & \mathbf{0} & \mathbf{0} & \mathbf{0} \\
\mathbf{0} & \mathbf{0} & \mathbf{Z}_{3} & \mathbf{0} & \mathbf{0} \\
\mathbf{0} & \mathbf{0} & \mathbf{0} & \mathbf{Z}_{4} & \mathbf{0} \\
\mathbf{0} & \mathbf{0} & \mathbf{0} & \mathbf{0} & \mathbf{Z}_{5}
\end{array}\right]\left[\begin{array}{l}
\mathbf{a}_{1} \\
\mathbf{a}_{2} \\
\mathbf{a}_{3} \\
\mathbf{a}_{4} \\
\mathbf{a}_{5}
\end{array}\right]+\left[\begin{array}{l}
\mathbf{e}_{1} \\
\mathbf{e}_{2} \\
\mathbf{e}_{3} \\
\mathbf{e}_{4} \\
\mathbf{e}_{5}
\end{array}\right]
$$

jossa mallin tekijät kuten mallissa (1). Alaindekseissä 1 on PK I, 2 on PK II, 3 on PK III, 4 on IES ja 5 on EK. Taulukossa 1 on esitetty ominaisuuksille käytetyt kiinteät tekijät. 
Taulukko 1. Tutkittaville ominaisuuksille käytetyt kiinteät tekijät

\begin{tabular}{lllll}
\hline & & PK & IES & EK \\
\hline & I & II & III & \\
tila-vuosi & $\checkmark$ & $\checkmark$ & $\checkmark$ & $\checkmark$ \\
syntymäajankohta (4 lk) & $\checkmark$ & & $\checkmark$ \\
paritustapa (luonnollinen tai ks.) & $\checkmark$ & $\checkmark$ & & \\
paritusten lkm (1 tai $>1$ ) & $\checkmark$ & $\checkmark$ & & $\checkmark$ \\
emän ikä (3 lk.) & & & & $\checkmark$ \\
sukupuoli (uros, naaras tai pentu) & & & & \\
\hline
\end{tabular}

PK = pentuekoko (I, II ja III), IES = ikä ensimmäistä kertaa siemennettäessä ja EK = eläimen koko

Yhden ominaisuuden analyyseissä satunnaistekijöiden varianssi-kovarianssimatriisiksi oletettiin:

$\operatorname{var}\left[\begin{array}{l}\mathbf{a} \\ \mathbf{c} \\ \mathbf{e}\end{array}\right]=\left[\begin{array}{ccc}\sigma_{\mathrm{a}}^{2} \mathbf{A} & \mathbf{0} & \mathbf{0} \\ \mathbf{0} & \sigma_{\mathrm{c}}^{2} \mathbf{I} & \mathbf{0} \\ \mathbf{0} & \mathbf{0} & \sigma_{\mathrm{e}}^{2} \mathbf{I}\end{array}\right]$

jossa $\sigma_{a}^{2}, \sigma_{c}^{2}$ ja $\sigma_{e}^{2}$ ovat additiivinen geneettinen varianssi, pentuevarianssi ja jäännösvarianssi, $\mathbf{A}$ additiivinen sukulaisuusmatriisi ja $\mathbf{I}$ on identiteettimatriisi. Monen ominaisuuden analyysissä varianssi-kovarianssimatriisiksi oletettiin:

$\operatorname{var}\left[\begin{array}{c}\mathbf{a} \\ \mathbf{c} \\ \mathbf{e}\end{array}\right]=\left[\begin{array}{ccc}\mathbf{G}_{0} \otimes \mathbf{A} & \mathbf{0} & \mathbf{0} \\ \mathbf{0} & \mathbf{C}_{0} \otimes \mathbf{I} & \mathbf{0} \\ \mathbf{0} & \mathbf{0} & \mathbf{R}_{0} \otimes \mathbf{I}\end{array}\right]$

jossa $\mathbf{G}_{0}$ on $5 \times 5$ additiivinen geneettinen varianssi-kovarianssimatriisi, $\mathbf{C}_{0}$ on pentuetekijään liittyvä $5 \times 5$ varianssi-kovarianssimatriisi ja $\mathbf{R}_{0}$ on jäännöstekijään liittyvä $5 \times 5$ varianssikovarianssimatriisi. Periytymisasteet $\left(\mathrm{h}^{2}\right)$ ja pentuevaihtelun osuus fenotyyppisestä vaihtelusta $\left(\mathrm{c}^{2}\right)$ laskettiin seuraavasti:

$\mathrm{h}^{2}=\sigma_{a}^{2} /\left(\sigma_{a}^{2}+\sigma_{c}^{2}+\sigma_{e}^{2}\right) \quad \mathrm{ja} \quad \mathrm{c}^{2}=\sigma_{c}^{2} /\left(\sigma_{a}^{2}+\sigma_{c}^{2}+\sigma_{e}^{2}\right)$

jossa $\sigma_{a}^{2}$ on additiivinen geneettinen varianssi, $\sigma_{c}^{2}$ on pentuevarianssi ja $\sigma_{e}^{2}$ on jäännösvarianssi.

\section{Tulokset ja tulosten tarkastelu}

Tutkittavien ominaisuuksien keskiarvot ja vaihtelu ovat esitetty taulukossa 1. PK I on noin 2.5 pentua pienempi kuin PK II ja PK III. Koska keskihajonta on kuitenkin samansuuruinen kolmessa ensimmäisessä pentuekoossa on vaihtelukerroin hiukan pienempi PK II:ssa ja PK III:ssa kuin PK I:ssa. Ero vaihtelukertoimissa on todennäköisesti seurausta ensimmäisen ja toisen penikoinnin välissä tehtävästä voimakkaasta valinnasta. Sinikettunaaraat siemennetään ensimmäisen kerran keskimäärin 320 päivän ikäisenä. IES:n vaihtelukerroin on selvästi pienempi kuin PK:ssa. Eläimen koon keskiarvo on 3.99, mikä viittaa siihen, että suuria arvoja annetaan hiukan liikaa.

Taulukko 1. Tutkittavien ominaisuuksien keskiarvo (ka), keskihajonta (sd), vaihtelukerroin (CV) sekä minimit ja maksimit

\begin{tabular}{llrrlll}
\hline omin. & & \multicolumn{1}{l}{ ka } & \multicolumn{1}{l}{ s.d } & CV & Minimi & Maksimi \\
\hline PK & I & 6.14 & 3.01 & 0.49 & 1 & 18 \\
& II & 8.68 & 3.38 & 0.39 & 1 & 19 \\
& III & 8.72 & 3.25 & 0.37 & 1 & 17 \\
IES & & 319.98 & 10.84 & 0.03 & 271 & 361 \\
EK & & 3.99 & 0.72 & 0.18 & 1 & 5 \\
\hline
\end{tabular}

PK = pentuekoko (I, II ja III), IES = ikä ensimmäistä kertaa siemennettäessä, EK = eläimen

koko 
Yhdenominaisuuden analyyseissä saadut periytymisasteet ja pentuetekijöiden osuudet fenotyyppisestä varianssista on esitetty Taulukossa 2 . Pentuekoon periytymisaste oli alhainen $(0.08 \pm 0.01)$, mutta vastasi kuitenkin hyvin Valberg Nordrumin (1993) ja Nikulan (2000) saamia tuloksia. Pentuetekijän osuus kokonaisvaihtelusta oli pieni $(0.03 \pm 0.01)$.

Taulukko 2. Eläimiä aineistossa ja sukupuussa, fenotyyppinen varianssi $\left(\sigma_{\mathrm{P}}^{2}\right)$, pentuetekijän osuus fenotyyppisestä varianssista $\left(c^{2}\right)$ keskivirheineen (s.e) sekä periytymisasteet $\left(h^{2}\right)$ keskivirheineen (s.e)

\begin{tabular}{lccccc}
\hline & \multicolumn{2}{c}{ Eläimiä } & & & \\
\cline { 2 - 3 } omin & aineistossa & sukupuussa & $\sigma_{\mathrm{P}}^{2}$ & $\mathrm{c}^{2} \pm$ s.e & $\mathrm{h}^{2} \pm$ s.e \\
\hline PK I & 30268 & 44297 & 9.20 & $0.03 \pm 0.01$ & $0.08 \pm 0.01$ \\
IES & 46295 & 62035 & 96.97 & $0.26 \pm 0.01$ & $0.16 \pm 0.01$ \\
EK & 68108 & 78775 & 0.67 & $0.10 \pm 0.00$ & $0.24 \pm 0.01$ \\
\hline
\end{tabular}

PK I= ensimmäinen pentuekoko, IES = ikä ensimmäistä kertaa siemennettäessä, EK = eläimen koko

Sinikettujen iästä ensimmäistä kertaa siemennettäessä ja erityisesti sen periytyvyydestä on kirjallisuudessa hyvin vähän tietoa. Sioilla ja lypsykarjalla ominaisuutta on kuitenkin tutkittu runsaasti. Raheja ym. (1989) saivat vastaavan periytymisasteen arvion hiehoille (0.12) kuin tässä tutkimuksessa saatiin siniketuille (0.16). Toisaalta Hanenberg ym. (2001) saivat korkeamman periytymisasteen sioille (0.32). Tässä tutkimuksessa pentuevaihtelun osuus (0.26) oli IES:ssä selvästi suurempi kuin periytymisaste. Pentuetekijä sisältää suurimman osan emän hoitokyvystä, pentujen välisestä kilpailusta ja pentueen sijainnista varjotalossa johtuvasta vaihtelusta. Kun pentuetekijä jätettiin mallista pois, nousi periytymisasteen arvio yli 0.40:n.

Eläimen koon periytymisasteen arvio oli alhaisempi kuin Kenttämiehen ja Smedsin (2002) tutkimuksessa. Wierzbicki (2000) sai kuitenkin vastaavia tuloksia aineiston probit muokkauksen jälkeen. Pentuetekijä selitti eläimen koossa esiintyvästä vaihtelusta noin $10 \%$.

Monen ominaisuuden analyysissä saadut periytymisasteet olivat hyvin lähellä yhden ominaisuuden analyyseissä saatuja (Taulukko 4). Periytymisasteiden keskivirheet olivat alhaisimpia EK:ssa ja IES:ssä (Taulukko 4), joissa oli eniten havaintoja (Taulukko 3). PK II:ssa ja PK III:ssa havaintoja oli valinnan vuoksi huomattavasti vähemmän, mutta periytymisasteisiin liittyvät keskivirheet eivät silti olleet kovin korkeita.

Taulukko 3. Havaintojen lukumäärät kussakin ominaisuudessa ja ominaisuusparissa monen ominaisuuden analyysissä

\begin{tabular}{|c|c|c|c|c|c|c|}
\hline \multirow[b]{3}{*}{ PK } & \multirow[b]{3}{*}{ I } & \multicolumn{3}{|c|}{ PK } & \multirow[b]{2}{*}{ IES } & \multirow[b]{2}{*}{ EK } \\
\hline & & $\mathrm{I}$ & II & III & & \\
\hline & & 9811 & & & & \\
\hline & II & 3446 & 7063 & & & \\
\hline & III & 1396 & 2141 & 3820 & & \\
\hline IES & & 9688 & 4242 & 1653 & 15379 & \\
\hline EK & & 4890 & 2992 & 1254 & 7429 & 15621 \\
\hline
\end{tabular}

PK (I, II ja III) = I, II ja III pentuekoko, IES = ikä ensimmäistä kertaa siemennettäessä, EK = eläimen koko. Sukupuussa oli 32356 eläintä.

EK:n ja IES:n välinen geneettinen korrelaatio oli -0.20 , eli geneettisesti suuret naaraat siemennetään pieniä naaraita nuorempina. IES:n geneettinen korrelaatio PK I:n, PK II:n ja PK III:n kanssa oli 0.26, 0.34 ja 0.26 . Toisin sanoen vanhoina ensimmäistä kertaa siemennettävät naaraat saavat suurempia pentueita kuin nuorina siemennettävät naaraat. EK:n geneettinen korrelaatio PK I:n, PK II:n ja PK III:n kanssa oli $-0.40,-0.40 \mathrm{ja}-0.23$, eli koon jalostusvalinta pienentää pentuekokoa. 
Taulukko 4. Periytymisasteet ja niiden keskivirheet (halkaisija), geneettiset korrelaatiot ja niiden keskivirheet (yläkolmio) ja fenotyyppiset korrelaatiot (alakolmio) monen ominaisuuden mallissa

\begin{tabular}{|c|c|c|c|c|c|c|}
\hline & & & PK & & & \\
\hline & & $\mathrm{I}$ & II & III & IES & EK \\
\hline PK & I & $0.08 \pm 0.02$ & $0.62 \pm 0.17$ & $0.51 \pm 0.24$ & $0.26 \pm 0.10$ & $-0.40 \pm 0.09$ \\
\hline & II & 0.18 & $0.08 \pm 0.03$ & $0.60 \pm 0.27$ & $0.34 \pm 0.13$ & $-0.40 \pm 0.12$ \\
\hline & III & 0.16 & 0.23 & $0.07 \pm 0.04$ & $0.26 \pm 0.18$ & $-0.23 \pm 0.16$ \\
\hline IES & & 0.08 & 0.04 & 0.00 & $0.18 \pm 0.02$ & $-0.20 \pm 0.06$ \\
\hline EK & & -0.07 & -0.07 & -0.01 & -0.02 & $0.25 \pm 0.02$ \\
\hline
\end{tabular}

PK (I, II ja III) = I, II ja III pentuekoko, IES = ikä ensimmäistä kertaa siemennettäessä, EK = eläimen koko.

\section{Johtopäätökset}

Suora fenotyyppinen valinta pentuekoon suhteen ei ole tehokasta alhaisen periytymisasteen vuoksi. Sen sijaan eläimen koon fenotyyppinen valinta on huomattavasti tehokkaampaa kohtalaisen periytymisasteen takia. Eläimen koon ja pentuekoon välillä on epäsuotuisa geneettinen korrelaatio. Mikäli jalostusvalinnassa ei huomioida hedelmällisyyttä, pienentää koon geneettinen kasvu ensimmäistä, toista ja kolmatta pentuekokoa.

Ensimmäisen, toisen ja kolmannen pentuekoon välinen geneettinen korrelaatio oli kaikissa tapauksissa korkea, mutta kuitenkin selvästi alle yhden. Jalostusarvostelun kannalta toistuvuusmallin oletukset geneettisen korrelaation suuruudesta ja varianssisuhteiden yhtäsuuruudesta eivät päde. Toisen ja kolmannen pentuekoon periytymisasteet ja varianssisuhteet olivat kuitenkin melko lähellä toisiaan. Pentuekoko onkin ehkä syytä jakaa kahdeksi ominaisuudeksi: yksivuotiaiden naaraiden pentuekoko sekä kaksivuotiaiden ja vanhempien naaraiden pentuekoko.

Ikä ensimmäistä kertaa siemennettäessä on kohtalaisesti periytyvä ominaisuus. Eläimen koon ja IES:n välillä on negatiivinen geneettinen korrelaatio. Koska IES:n geneettinen korrelaatio pentuekoon kanssa on positiivinen, IES:n ja eläimen koon välinen geneettinen yhteys on tulkittava epäsuotuisaksi.

Siniketun koko arvioidaan syksyllä juuri ennen nahkontaa, jolloin eläimen kasvu on taittumassa. Koska suuret eläimet ovat kasvaneet nopeammin kuin pienet eläimet, on suuren koon valitseminen myös kasvunopeuden valitsemista. Nopeasti kasvavat eläimet saavuttavat riittävän parituspainon aikaisemmin kuin hitaasti kasvavat yksilöt. Koska arviointi on silmävaraista, saatetaan myös lihavuus tulkita suureksi kooksi. Näin ollen suuren koon valitsemisella saatetaan myös valita helposti rasvoittuvia yksilöitä, eli korostetaan siniketuille tyypillistä taipumusta kerätä rasvakudosta talvea varten. Useimmilla eläinlajeilla lihavuus heikentää hedelmällisyyttä. Kasvun koostumuksen ja kasvukäyrän muodon vaikutus hedelmällisyyteen on kuitenkin selvitettävä tarkemmin ennen vahvoja johtopäätöksiä.

\section{Kirjallisuus}

Hanenberg, E., H., A., T., Knol, E., F. ja Merks, J., W., M. 2001. Estimates of genetic parameters for reproduction traits at different parities in Dutch Landrace pigs. Livestock Production Science, 69(2): 179-186.

Kenttämies, H. ja Smeds, K. 2002. Correlated responses in litter result, body size, fur quality and colour clarity in blue foxes (Alopex lagopus) selected for confident behaviour. 7 th World Conferess on Genetics Applied to Livestock Production, August 19-23, 2002, Montpellier, France.

Lagerqvist, G, Johansson, K. ja Lundeheim, M. 1994. Selection for litter size, body weight, and pelt quality in mink (Mustela vison): correlated responses. Journal of Animal Science 72: 1126-1137.

Madsen, P. ja Jensen, J. 2000. A user's quide to DMU, a packade for analyzing multivariate mixed models, Danish Institute of Agricultural Sciences (DIAS). Tjele, Denmark. Mimeo $22 \mathrm{~s}$.

Nikula, S. 2000. Kettujen luonteen periytyvyys ja yhteys hedelmällisyysominaisuuksiin. Pro Gradu -työ. Helsingin Yliopiston kotieläintieteen laitoksen julkaisuja 48. $31 \mathrm{~s}$.

Peura, J. ja Strandén, I. 2003. Siniketun kokoa jalostetaan hedelmällisyyden kustannuksella. Turkistalous 75(8-9):13-15

Raheja, K.L., Burnside, E.B. ja Schaeffer, L.R. 1989 Heifer fertility and its relationship with cow fertility and production traits in holstein dairy cattle. Journal of Dairy Science 72: 2665-2669.

Valber Nordrum, N. 1993 Genetic and endocrinological factors influencing reproduction in blue foxes. Agricultural University of Norway. Doctor Scientarum Theses 1993:7.

Wierzbicki, H. 2000. Additive genetic and error variance components for conformation and coat traits in arctic fox Alopex lagopus (L.). Scientifur 24(3): 217-222. 